BNL-113851-2017-CP

File \# 94809

\title{
Dynamic characterization of structural changes in vapochromic compounds by pair distribution function
}

\author{
R. Caliandro, B. D. Belviso, C. Cuocci, S. Fuertes, V. Sicilia, \\ J. C. Hanson, G. Tutuncu, E. Doorhyee, and A. Altomare
}

Presented at EPDIC-15 Conference

Bari, Italy,

June 12-15, 2016

January 2017

Photon Sciences Department

Brookhaven National Laboratory

\author{
U.S. Department of Energy \\ USDOE Office of Science (SC), \\ Basic Energy Sciences (BES) (SC-22)
}

Notice: This manuscript has been authored by employees of Brookhaven Science Associates, LLC under Contract No. DE- SC0012704 with the U.S. Department of Energy. The publisher by accepting the manuscript for publication acknowledges that the United States Government retains a non-exclusive, paid-up, irrevocable, world-wide license to publish or reproduce the published form of this manuscript, or allow others to do so, for United States Government purposes. 


\section{DISCLAIMER}

This report was prepared as an account of work sponsored by an agency of the United States Government. Neither the United States Government nor any agency thereof, nor any of their employees, nor any of their contractors, subcontractors, or their employees, makes any warranty, express or implied, or assumes any legal liability or responsibility for the accuracy, completeness, or any third party's use or the results of such use of any information, apparatus, product, or process disclosed, or represents that its use would not infringe privately owned rights. Reference herein to any specific commercial product, process, or service by trade name, trademark, manufacturer, or otherwise, does not necessarily constitute or imply its endorsement, recommendation, or favoring by the United States Government or any agency thereof or its contractors or subcontractors. The views and opinions of authors expressed herein do not necessarily state or reflect those of the United States Government or any agency thereof. 


\title{
Dynamic characterization of structural changes in vapochromic compounds by pair distribution function
}

R. Caliandro ${ }^{1, \text { a) }}$, B.D. Belviso ${ }^{1}$, C. Cuocci $^{1}$, S. Fuertes ${ }^{2}$, V. Sicilia ${ }^{2}$, J.C. Hanson ${ }^{3}$, G. Tutuncu ${ }^{4}$, E. Doorhyee ${ }^{4}$ A. Altomare ${ }^{1}$

\author{
${ }^{1}$ Institute of Crystallography, CNR, Bari, Italy \\ ${ }^{2}$ Departamento de Química Inorgánica, Universidad de Zaragoza-CSIC, Zaragoza, Spain \\ ${ }^{3}$ Chemistry Department, Brookhaven National Laboratory, NY, United States \\ ${ }^{4}$ NSLS II, Photon Science Division, Brookhaven National Laboratory, NY, United States
}

a) Author to whom correspondence should be addressed. Electronic mail: rocco.caliandro@ic.cnr.it

\begin{abstract}
Two examples of anionic complexes having vapochromic behavior are investigated: $\left[\mathrm{K}\left(\mathrm{H}_{2} \mathrm{O}\right)\right]\left[\mathrm{Pt}(\mathrm{ppy})(\mathrm{CN})_{2}\right] \quad$ "Pt(ppy)" and $\left[\mathrm{K}\left(\mathrm{H}_{2} \mathrm{O}\right)\right]\left[\mathrm{Pt}(\mathrm{bzq})(\mathrm{CN})_{2}\right] \quad$ "Pt(bzq)", where ppy=2phenylpyridinate and bzq=7,8-benzoquinolate. These monohydrate-potassium salts exhibit a change in color from purple to yellow (Pt(ppy)) and from red to yellow (Pt(bzq)) upon heating to $110{ }^{\circ} \mathrm{C}$, and they transform back into the original color upon absorption of water molecules from the environment. Available only in the form of polycrystalline samples, no structural information on such compounds is accessible, due to highly overlapping peaks in powder diffraction profiles. We use in-situ PDF measurements on powder samples to investigate the dynamics of the structural changes induced by temperature variations. By means of a multivariate approach, we were able to extract dynamic structural information from collected profiles without using prior knowledge on the static crystal structure of the compounds. The critical temperature and the characteristics of the vapochromic transition have been identified, as well as the main structural changes causing it.
\end{abstract}

Keywords: vapochromic compounds, structural transitions, pair distribution function, multivariate analysis. 


\section{INTRODUCTION}

Vapochromic materials are promising candidates for intelligent devices, such as "electronic noses" that can detect volatile organic compounds (VOCs) in the environment. Ideally, such materials would not only detect VOCs below the part per million (ppm) level, but would also show a unique response for each VOC. Of particular interest are responsive compounds that show dramatic and reversible color changes upon exposure to VOCs. These materials exhibit reversible structural changes triggered by vapor uptake, which are accompanied by a dramatic color change of the solid allowing the detection of VOCs even by naked eye. This has been demonstrated with various metal compounds, such as $\mathrm{Pt}(\mathrm{II})$-containing cyclometalated complexes. One approach to assemble these complexes is to utilize coordination polymerization reactions, by tuning the bond strength with appropriate assembly of metal ions and coordinating Pt(II) and Pd(II) metalloligands (Buss et al., 1998; Daws et al., 1997; Kobayashi \& Kato, 2014; Wenger, 2013). Coordination polymers $\left[\mathrm{K}\left(\mathrm{H}_{2} \mathrm{O}\right)\right]\left[\mathrm{Pt}(\mathrm{ppy})(\mathrm{CN})_{2}\right]$ and $\left[\mathrm{K}\left(\mathrm{H}_{2} \mathrm{O}\right)\right]\left[\mathrm{Pt}(\mathrm{bzq})(\mathrm{CN})_{2}\right]$ (where ppy=2-phenylpyridinate and bzq=7,8benzoquinolate) are two examples of anionic complexes exhibiting vapochromism. These monohydrate-potassium salts are soluble in water and vary in color, $\mathrm{Pt}(\mathrm{ppy})$ being purple and Pt(bzq) being red (Forniés et al., 2008). Upon heating to $110^{\circ} \mathrm{C}$, these compounds lose the crystal water and experience a change in color from purple ( $\mathrm{Pt}(\mathrm{ppy}))$ or red $(\mathrm{Pt}(\mathrm{bzq}))$ to yellow. When the anhydrous species are exposed to the air, they undergo inverse changes of color within seconds due to water molecules uptake. The origin of this vapochromic behavior is thought to be related to the altered metallophilic Pt-Pt interactions upon solvent absorption. However, so far only the Pt(ppy) precursor complex has been structurally characterized (Forniés et al., 2008). In this study in situ Pair Distribution Function (PDF) measurements were performed at Brookhaven National Laboratory by varying the temperature on the sample. The dynamics of the structural changes for each of the four compounds studied here were characterized via multivariate analysis of the PDF data (Caliandro \& Belviso, 2014). The structural information obtained provides further insight into strategies to achieve engineered vapochromic complexes, which selectively and rapidly respond to specific vapors in small quantities.

\section{SAMPLES DESCRIPTION AND SPECTROSCOPIC CHARACTERIZATION} Compounds $\left[\mathrm{K}\left(\mathrm{H}_{2} \mathrm{O}\right)\right]\left[\mathrm{Pt}(\mathrm{ppy})(\mathrm{CN})_{2}\right]$ and $\left[\mathrm{K}\left(\mathrm{H}_{2} \mathrm{O}\right)\right]\left[\mathrm{Pt}(\mathrm{bzq})(\mathrm{CN})_{2}\right]$ were prepared according to what reported in Forniés et al., (2008), and characterized by IR, ${ }^{1} \mathrm{H}$ NMR and UV-vis spectroscopy. Specially significant are the presence in their IR of two $v_{\mathrm{CN}}$ absorptions around $2100 \mathrm{~cm}^{-1}$ and 2120 $\mathrm{cm}^{-1}$, corresponding to two terminal $\mathrm{CN}$ ligands in a cis arrangement and a strong absorption at $3400 \mathrm{~cm}^{-1}$ indicative of the presence of water in the solid (Forniés et al., 2008). The amount of 
water can be determined from their ${ }^{1} \mathrm{H}$ NMR spectra in non-water containing acetone- $d_{6}$, which in addition to the signals corresponding to the bzq or ppy group show one signal at about 2.9 ppm, corresponding to one molecule of water (Forniés et al., 2008).

The UV-vis spectra of each one of these compounds in the solid state show intense absorptions at $\lambda$ $<450 \mathrm{~nm}$ assigned to IL/MLCT transitions and an intense absorption at $\lambda=564 \mathrm{~nm}[\mathrm{Pt}(\mathrm{ppy})]$ or 548 $\mathrm{nm}[\mathrm{Pt}(\mathrm{bzq})]$ (Forniés et al., 2008). The latter is assigned to ${ }^{1} \mathrm{MMLCT}\left[\mathrm{d} \sigma^{*}(\mathrm{Pt}) \rightarrow \pi^{*}(\mathrm{CN})\right]$ transitions, and it is the responsible for the intense color showed by these compounds; it also is considered as the fingerprint of the existence of short Pt · Pt contacts (3.0 - $3.5 \AA)$ in the $\mathrm{z}$ axis. Upon heating compounds $\left[\mathrm{K}\left(\mathrm{H}_{2} \mathrm{O}\right)\right]\left[\mathrm{Pt}(\mathrm{ppy})(\mathrm{CN})_{2}\right]$ and $\left[\mathrm{K}\left(\mathrm{H}_{2} \mathrm{O}\right)\right]\left[\mathrm{Pt}(\mathrm{bzq})(\mathrm{CN})_{2}\right]$ in the oven at $110^{\circ} \mathrm{C}$, the anhydrous species were obtained, which exhibit a yellow color. The absence of water in the solid can be probed by IR and ${ }^{1} \mathrm{H}$ NMR spectra in non-water containing acetone- $d_{6}$.

Their UV-vis spectra in the solid state show the absence of the lowest energy absorption assigned to the ${ }^{1}$ MMLCT transitions, being indicative of the profound structural changes operating in the solids by the loss of the water molecules.

The observed color changes for the $\operatorname{Pt}(\mathrm{bzq})$ and $\mathrm{Pt}(\mathrm{ppy})$ samples are summarized in Figure 1. Vapochromic transitions manifest themselves with dramatic color changes, and can be achieved by heating the samples or putting them in vacuum. Reverse transitions are obtained by allowing water molecules in air to interact with the powder sample. The Pt ligands are depicted in Figure 2. They exhibit very similar structure, with only two added carbon atoms present in bzq, which complete a third aromatic ring. Samples were mounted on quartz capillaries of $1 \mathrm{~mm}$ diameter for X-ray diffraction experiments.

\section{DIFFRACTION EXPERIMENTS}

\section{A. Data collection}

X-ray data were collected at the X17A beamline of the National Synchrotron Light Source (NSLS) at Brookhaven National Laboratory with a X-ray energy of $66.7 \mathrm{keV}(0.18597 \AA$ ) and $0.5 \mathrm{~mm}$ x 0.5 mm beam size. A large 2D Perkin Elmer area detector (2048x2048 pixels and 200 x $200 \mu \mathrm{m}$ pixel size) was mounted orthogonal to the beam path, $202 \mathrm{~mm}$ downstream from the sample. Lanthanum hexaboride was measured as standard material to calibrate the sample and detector geometry, including the sample-to-detector distance. The temperature was first increased from $20^{\circ} \mathrm{C}$ to $150{ }^{\circ} \mathrm{C}$ and then decreased to $20^{\circ} \mathrm{C}$ by using a cryo-cooler. A step of $5^{\circ} \mathrm{C}$ was done every 10 minutes, during which a complete measurement and a monochromator realignment were automatically performed. Each data collection lasted about 2 minutes, and in the remaining 8 minutes the X-ray 
shutter was closed to avoid radiation damage of the samples. An empty capillary was measured for background estimation.

\section{B. Data analysis}

Raw 2D data were azimuthally integrated and converted into 1D intensity versus $2 \vartheta$ and versus momentum transfer $Q=4 \pi \sin \vartheta / \lambda$ by using the FIT2D program (Hammersley et al., 1996). PDF profiles were calculated from the $Q$ profiles by the program PDFGetX3 (Juhás et al., 2013). Timedependent PDF profiles were processed by the program RootProf (Caliandro \& Belviso, 2014) to perform qualitative analysis through principal component analysis (PCA). It is a projection method (Wold et al., 1987), which can be used to reduce the dimensionality of the data set constituted by the measured profiles. Principal components (PCs) are calculated as eigenvectors of the covariance matrix of the data, whose eigenvalues represent the variance of the data along the eigenvector directions. The initial dimensionality of the data set, equal to the number of $2 \theta$ values used to describe the diffraction profiles $(\mathrm{N})$, is reduced to $\mathrm{n}$, representing the number of PCs used. Score and loading vectors are two alternative representations of the data matrix: the former carry information about samples (measurements) in variable (20) space, the latter about variables in sample space.

\section{RESULTS AND DISCUSSION}

PDF profiles obtained at different temperatures for sample Pt(bzq) and $\mathrm{Pt}(\mathrm{ppy})$ are superimposed in Figure 3, where abrupt changes can be revealed, indicating the occurrence of relevant structural changes in the compounds. It is worthwhile noticing that variations in the PDF profiles manifest themselves for interatomic distances above $3 \AA$, while an almost perfect overlap occurs at shorter distances. As suggested by Rademacher et al., (2012), the PDF profiles can be ideally divided into three regions: below $3 \AA$, where only intramolecular distances are present; between 3 and $8 \AA$, where intra-molecular and intermolecular distances overlap, and beyond $8 \AA$, where only intermolecular distances are present. The three regions show increasing variations in the PDF profiles, indicating that the molecule itself does not change its conformation upon heating, while the crystal packing is strongly influenced by such external perturbation, and the mutual position of different molecules in the crystal is varied. In the intermolecular distances region, in particular, PDF curves tend to flatten as the temperature is increased, remaining almost constant for higher temperatures. This indicates a decrease of the structural order at long range, due to a deterioration of the crystal lattice. Another striking feature arising from the analysis of Figure 3 is the similarity 
between the PDF functions of the two compounds, which suggest a similar molecular arrangement within the crystals.

A detailed investigation of the variations of the PDF curves as a function of the temperature can be carried out by using the differential approach, i.e. by subtracting the starting PDF from the subsequent ones to highlight the residual that corresponds to the structural part which is changing with temperature. We implemented such an approach by using all PDF profiles together, given as input for principal component analysis. The results for $\mathrm{Pt}(\mathrm{bzq})$ and $\mathrm{Pt}(\mathrm{ppy})$ are shown in Figure 4 and 5, respectively, where the PCA scores (left) and loadings (right) are reported as a function of the measurement number and of the interatomic distance, respectively. The main features of the PDF profiles are captured by the first principal component (PC), which explains $89.1 \%$ and 95.1\% of the total data variance for Pt(bzq) and Pt(ppy), respectively. The PC1 scores supply the dynamic trend of the structural variations during measurements. It can be noted that an abrupt change occurs around measurement n. 9 for $\mathrm{Pt}(\mathrm{bzq})$ and n. 17 for $\operatorname{Pt}(\mathrm{ppy})$, and that no change occur at later measurements, while the temperature is ramped down. This indicates that during in situ heating/cooling process, reverse transitions were not attained upon returning to the initial temperature on the sample. Such behavior can be attributed to an uneven air flow within the capillary. In fact, after unmounting the sample we observed a color change confined to the region of the capillary hit by the X-ray beam, indicating that the water molecules have only reached the more exposed powder in the capillary. It is worthwhile noting that the reverse sign of the PC1 scores and loadings of $\mathrm{Pt}(\mathrm{ppy})$ with respect to those of $\mathrm{Pt}(\mathrm{bzq})$ is not significant, given that the scores and loadings calculated by PCA have a sign ambiguity.

The PC1 loadings represent the PDF signal associated to the kinetic behavior captured by the PC1 scores. For both Pt(bzq) and Pt(ppy), they satisfy basic expectations for typical PDF profiles, which have been listed by Chapman et al., (2015) as: absence of negative intensity peaks, envelope with decreasing peak amplitude at high interatomic distances and limited presence of high-frequency components ( $v \approx 2 \pi / Q_{\max }$ ). Thus the PC1 loadings represent the part of the crystal structure which is involved in the vapochromic changes. Interestingly, the sharp peaks of the PC1 loadings for the two compounds have the same positions (taking into consideration the above mentioned sign ambiguity), indicating similar structural changes triggered by temperature variations. The first peak occurs at an interatomic distance of about $3.2 \AA$, which is consistent with the typical Pt-Pt bond distance and thus it is reasonable to assign the presence of such peaks to Pt-Pt intra-molecular distances within the crystal packing. As a consequence, the main structural variations related to vapochromic transitions are due to altered Pt-Pt distances in the crystal lattice. Such evidence is in agreement with previous investigations of the optical properties of these compounds (Forniés et al., 
2008). On the other hand, the color of the complexes strongly depends on the intermolecular distance between $\mathrm{Pt}(\mathrm{II})$ ions.

Subsequent principal components in Figure 4 have loadings with large deviations from typical experimentally derived PDF curves. In particular, they are dominated by high-frequency signals, close to $v \approx 2 \pi / Q_{\max }$, which is the characteristic periodicity in $\mathbf{r}$ space of ripple artefacts arising from Fourier transformations of scattering factors measured up to $Q_{\max }$ (Chapman et al., 2015). In other words, these components represent noise in the data, in increasing amount for higher components. The higher principal components of $\operatorname{Pt}($ ppy) shown in Figure 5 are instead significantly different from those of Pt(bzq). The PC2 loadings, and at a lesser extend the PC3 ones, have positive peaks above a linear baseline and lack high-frequency components. They follow the typical envelope of experimentally derived PDF curves, with peak intensity decreasing with the interatomic distance. These components thus reflect secondary structural changes different from those captured by PC1. It is interesting to note that they have major contribution from peaks at interatomic distances of about $1.8 \AA$, thus involving intramolecular distances only. In addition, the PC2 and PC3 scores reveal that such structural changes do not occur abruptly around the transition temperature, like in PC1, but they rather follow the temperature variations exerted on the sample during the in situ heating. In fact, the PC2 scores increase almost linearly up to measurement n.15, and then decrease up to the last measurement, where the initial value is reached. A similar trend is followed by the PC3 scores.

The dynamics of the main structural variations involved in the vapochromic transitions can be investigated by plotting the PC1 scores versus the temperature values associated to the different measurements. In doing this, we are allowed to rescale the PC1 scores values by arbitrary constants and change their sign, as they are calculated in arbitrary units. Such study, reported in Figure 6 by using only the measurements with increasing temperature, reveals that the vapochromic transitions of the two compounds have different characteristics. The critical temperature of the Pt(bzq) compound, i.e. the temperature at which the PC1 curve has a flex, is about $340 \mathrm{~K}$, while that of the $\mathrm{Pt}$ (ppy) compound is about $378 \mathrm{~K}$. Besides the higher transition temperature, the two vapochromic transitions have a different mechanism of structural transformations, related to the slope of the characteristic curves around the critical temperature. That of Pt(bzq) occurs abruptly between the two states,; that of Pt(ppy) has a more smooth trend, which points to a transition which is accompanied by structural distortions occuring beside the main structural changes. Such behavior reflects the above considerations on subsequent principal components different from noise in the Pt(ppy) case. 


\section{CONCLUSIONS}

The characteristic curves describing the dynamics of the transition have been derived by using the multivariate analysis approach applied on in situ X-ray PDF measurements. The analysis of such curves has allowed to find the characteristic temperature of the transitions and to guess about the underlying mechanism. These two features depend strongly on the ligand forming the vapochromic compound, with the bzq ligand triggering a sharper transition occurring at lower temperature, the ppy one triggering a smoother transition occurring at a $38 \mathrm{~K}$ higher temperature. Moreover, the general features shown by the loadings of the first principal component indicate that the Pt-Pt contacts play a major role in determining the structural changes. For the Pt(ppy) compound, such changes are accompanied by structural distortion of the ligand structure, evidenced by principal components of higher order. We plan to perform static structural investigations by using X-ray powder diffraction on the same compounds, which could corroborate such findings.

\section{ACKNOWLEDGEMENTS}

Use of the National Synchrotron Light Source, Brookhaven National Laboratory, was supported by the U.S. Department of Energy, Office of Science, Office of Basic Energy Sciences, under Contract No. DE-AC02-98CH10886. This research has been partially supported by the short-term mobility CNR program. 


\section{References}

Altomare A., Caliandro R., Camalli M., Cuocci C., Giacovazzo C., Moliterni A.G.G., Rizzi R. (2004). “Automatic structure determination from powder data with EXPO2004,” J. Appl. Cryst. 37, 1025-1028.

Altomare A., Caliandro R., Cuocci C., Giacovazzo C., Moliterni A.G.G., Rizzi R., Platteau C. J. (2008). "Direct methods and simulated annealing: a hybrid approach for powder diffraction data,” Appl. Cryst. 41, 56-61.

Buss, C.E., Anderson, C.E., Pomije, M.K., Lutz, C.M., Britton, D., Mann, K.R. (1998). “Structural investigations of vapochromic behavior. X-ray single-crystal and powder diffraction studies of $\left[\mathrm{Pt}\left(\mathrm{CN}-\mathrm{iso}_{-} \mathrm{C}_{3} \mathrm{H}_{7}\right)_{4}\right]\left[\mathrm{M}(\mathrm{CN})_{4}\right]$ for $\mathrm{M}=\mathrm{Pt}$ or Pd.,” J. Am. Chem. Soc 120, 7783-7790.

Caliandro R., and B.D. Belviso (2014). "RootProf: software for multivariate analysis of unidimensional profiles,” J. Appl. Cryst. 47, 1087-1096.

Chapman K.W., Lapidus, S.H., Chupas, P.J. (2015). “Applications of principal component analysis to pair distribution function data,” J. Appl. Cryst. 48, 1619-1626.

Daws, C.A., Exstrom, C.L., Sowa, J.R., Mann, K.R. (1997). "Vapochromic compounds as environmental sensors. 2. Synthesis and nearinfrared and infrared spectroscopy studies of $\left[\mathrm{Pt}(\text { arylisonitrile })_{4}\right] \mathrm{x}\left[\mathrm{Pt}(\mathrm{CN})_{4}\right]$ upon exposure to volatile organic compounds vapors,” Chem. Mater. 91, 363-368.

Forniés J., Fuertes, S., López, J.A., Martín, A and Sicilia V. J. (2008). “New water soluble and luminescent platinum(II) compounds, vapochromic behavior of [K(H2O)][Pt(bzq)(CN)2], new examples of the influence of the counterion on the photophysical properties of d8 squareplanar complexes,” Inorg.Chem. 47, 7166-7176.

Hammersley, A.P., Svensson, S.O., Hanfland M., Hauserman, D. (1996). “Two-dimensional detector software: From real detector to idealised image or two-theta scan,” High Press. Res. 14, 235-248.

Kobayashi, A., Kato, M. (2014). "Vapochromic Platinum(II) Complexes: Crystal Engineering toward Intelligent Sensing Devices,” Eur. J. Inorg. Chem. 4469-4483. doi:10.1002/ejic.201402315.

Juhás, P., Davis, T., Farrow, C. L., Billinge, S. J. L. (2013). “PDFgetX3: a rapid and highly automatable program for processing powder diffraction data into total scattering pair distribution functions” J. Appl. Cryst. 46, 560-566. 
Rademacher, N., Daemen, L. L., Chronisterc E.L., Proffen, T. (2012) “Pair distribution function analysis of molecular compounds: significance and modeling approach discussed using the example of p-terphenyl,” J. Appl. Cryst. 45, 482-488.

Wenger, O.S., (2013) "Vapochromism in Organometallic and Coordination Complexes: Chemical Sensors for Volatile Organic Compounds,” 113, 3686-3733.

Wold, S., Esbensen, K. \& Geladi, P. (1987). “Principal Component Analysis,” Chemom. Intell. Lab. Syst. 2, 37-52. 